
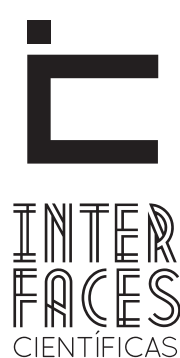

EDUCAÇÃO

ISSN IMPRESSO 2316-333X

E-ISSN 2316-3828

DOI-10.17564/2316-3828.2017v5n2p9-18

\title{
A RELAÇÃO ESPAÇO/IDENTIDADE EM NARRATIVAS ACADÊMICAS SOBRE OS BOLIVIANOS EM SÃO PAULO
}

THE RELATION SPACE/IDENTITY IN ACADEMIC NARRATIVES ABOUT THE BOLIVIANS IN SÃO PAULO

LA RELACIÓN ESPACIO/IDENTIDAD EN DISCURSOS ACADÉMICOS ACERCA DE LOS BOLIVIANOS EN SÃO PAULO

Priscila da Silva Santos ${ }^{1}$

\section{RESUMO}

Este texto trata da identidade linguística a partir de três artigos sobre imigração boliviana na cidade de São Paulo, Brasil. A análise destes artigos permite que se esboce como a identidade linguística dos bolivianos que habitam a metrópole paulistana é construída pela narrativa acadêmica. Nesta narrativa estão presentes questões relativas à luta por espaços para o exercício da cultura, do trabalho e da educação e, em cada um destes espaços a identidade linguística dos imigrantes bolivianos assume diferentes características.

\section{PALAVRAS-CHAVE}

Imigração. Bolivianos. Identidades Linguísticas. 


\section{ABSTRACT}

This text is about linguistic identity based in three articles that deal with Bolivian immigration in São Paulo, Brazil. The analysis of these articles makes possible to outline how the linguistic identities of Bolivians who live in metropolitan area of São Paulo are constructed by academic narrative. Issues related to fight for places to practice culture, work and education are present in this narrative. Therefore the linguistic iden- tity of Bolivian immigrants assumes different characteristics in each of these spaces.

\section{KEYWORDS}

Immigration. Bolivians. Linguistic identities.

\section{RESUMÉN}

Este texto se ocupa de la identidad lingüística a partir de tres artículos sobre la inmigración boliviana en la ciudad de São Paulo, Brasil. El análisis de estos artículos permite esbozar como la identidad lingüística de los bolivianos que viven en la metrópoli, se construye por la narrativa académica. En esta narrativa están presentes cuestiones a propósito de la lucha por espacios para el ejercicio de la cultura, trabajo y educación, en cada uno de esos espacios la identidad lingüística de los migrantes bolivianos asume diferentes características.

\section{PALABRAS CLAVE}

Inmigración, bolivianos, identidad linguística. 


\section{INTRODUCÇÃO}

0 presente artigo constitui parte de um projeto de pesquisa de doutorado no qual se pretende, a partir de narrativas orais produzidas por estudantes bolivianos inseridos no ensino público regular do município de São Paulo, investigar a questão linguístico-identitária destes imigrantes, cuja chegada ao Brasil tenha ocorrido nas duas últimas décadas. A partir da exploração destas narrativas (registradas em vídeo), esperamos depreender como se configuram os mecanismos de pluralização da identidade linguística destes bolivianos no contexto da instituição escolar.

Neste artigo, escrito antes que o trabalho de campo tenha se iniciado e sem que os depoimentos tenham sido coletados, tomaremos como objeto de análise três artigos: Bolivianos em São Paulo: dinâmica cultural e processos identitários, de Sydney A. Silva (ARTIGO 1), Imigrantes da Bolívia na escola em São Paulo: Fronteiras do direito à educação, de Giovanna Modé Magalhães e Flávia Schilling (ARTIGO 2) e A comunidade boliviana em São Paulo: definindo padrões de territorialidade, de Renato Cymbalista e lara Ronilk Xavier (ARTIGO 3).

O contato com os artigos deu-se a partir da pesquisa bibliográfica que estamos realizando sobre o que já se produziu - no âmbito acadêmico, a respeito da crescente imigração boliviana na cidade de São Paulo. Não há um consenso numérico entre os diversos órgãos quanto à imigração boliviana na metrópole paulistana: o Consulado da Bolívia estima a existência de 50 mil bolivianos indocumentados, a Pastoral do Imigrante calcula 70 mil indocumentados; para o Ministério do Trabalho e Emprego este número varia entre 10 e 30 mil, já o Ministério Público estima que em São Paulo vivam cerca de 200 mil bolivianos (regulares e irregulares). O fato é que os bolivianos constituem, atualmente, a segunda maior colônia de estrangeiros da cidade, ficando atrás apenas dos portugueses.
Tal dinâmica migratória tem despertado o interesse de pesquisadores de diversas áreas tais como a Antropologia, a Geografia, a Sociologia e também da Educação. Sendo assim, pretendemos, a partir dos artigos selecionados, investigar como se constitui a identidade dos bolivianos nestas narrativas acadêmicas. Para tanto, realizaremos recortes sobre os artigos, estabelecendo comparações entre eles, a partir da perspectiva do espaço narrativo.

\section{DOS ARTIGOS COMO NARRATIVAS DE POSSÍVEIS IDENTIDADES}

Primeiramente, cabe fazer uma breve descrição dos artigos. 0 primeiro deles, de Silva, Bolivianos em São Paulo: dinâmica cultural e processos identitários, procura investigar o processo de ressignificação cultural realizado por algumas associações fundadas por imigrantes bolivianos com a intenção de combater a imagem que deles têm sido veiculada por meio da mídia. Segundo o autor, os preconceitos divulgados pela mídia têm a ver com a associação dos bolivianos ao regime de trabalho análogo à escravidão.

O segundo artigo, de Magalhães e Schilling, Imigrantes da Bolívia na escola em São Paulo: fronteiras do direito à Educação se propõe a verificar o cumprimento dos critérios estabelecidos pelo Comitê de Direitos Econômicos, Sociais e Culturais (DESC) das Nações Unidas. Os critérios são os chamados "4 As" (Available, Acessible, Acceptable, Adaptable), segundo tais critérios, seria possível definir a garantia ou não do direito à educação.

O terceiro, por fim, A comunidade boliviana em São Paulo: definindo padrões de territorialidade, de Cymbalista e Xavier (2007), investiga os padrões de inserção territorial da comunidade boliviana a partir 
de classificações internacionalmente reconhecidas, tais como gueto, banlieues, enclave étnico e contingente de desalojados.

Os artigos citados, doravante $A 1, A 2$ e $A 3$, serão tomados como narrativas. A concepção de narrativa aqui adotada baseia-se, principalmente, em Bruner (2002, p. 8): "All I want to say for the moment is that narrative, including fictional narrative, gives shape to things in the real world and often bestows on them a title to reality".

Para fins de análise, tomaremos os artigos-narrativas como credenciais de acesso à construção da realidade a partir do espaço. Com isso queremos dizer que o fio condutor, o vínculo entre os três artigos será o espaço onde estão inseridos os bolivianos com os quais os pesquisadores tiveram contato. Todos os pesquisadores utilizaram a entrevista como uma das metodologias de pesquisa.

Nos três textos temos a predominância dos personagens "bolivianos" em três espaços distintos: o espaço cultural em A1, o espaço escolar em A2 e o espaço laboral em A3. Devemos deixar claro que a classificação espacial aqui proposta se deu segundo critérios de predominância, pois os artigos citam espaços diversos.

No que se refere à identidade apoiaremo-nos, fundamentalmente, em Mignolo (2008), pois a oposição por ele estabelecida entre "política de identidade" e "identidade em política" revelou-se relevante para a análise das narrativas aqui tomadas como objeto, uma vez que cada uma delas, a seu modo, aponta para a preocupação com a formulação ou aprimoramento de políticas que tornem efetiva a integração dos imigrantes bolivianos no município de São Paulo.

Segundo Mignolo (2008, p. 300), a "política de identidade" opera a partir de uma identidade essencial das classes marginalizadas. Segundo esta lógica, universais abstratos elaboram-se, apresentam-se como bons para a humanidade inteira, "isto significa que a defesa da similaridade humana sobre as dife- renças humanas é sempre uma reivindicação feita pela posição privilegiada da política de identidade no poder". Já a "identidade em política" parte da ruptura com o pensamento fundamentado no grego e no latim e com a classificação étnica sobre a qual se erigiram os estados-nação desde o início do século XIX, a fim de substituir uma geografia da razão por uma regionalização da consciência. Em outras palavras, o autor problematiza a racialização dos corpos e a fixidez das localidades geo-históricas propondo uma descolonização epistêmica, uma "consciência mestiça”.

O nosso objeto é fruto de uma tradição lógica racionalista ocidental "o artigo científico" (que por sinal está sendo tratado num artigo que se quer igualmente científico), tendo como tema a questão da imigração boliviana na cidade de São Paulo e o modo como as identidades desses imigrantes vêm sendo narradas na esfera acadêmica e, finalmente, discutindo a partir do escopo espacial a constituição de tais identidades; as contribuições de Mignolo nos parecem muito bem vindas. Partamos então, às narrativas acadêmicas.

\section{ESPAÇO CULTURAL: A IDENTIDADE NÔMADE}

O artigo de Silva (BAENINGER, 2012) narra a busca dos imigrantes bolivianos por locais nos quais pudessem realizar suas manifestações culturais. Consta em A1 que antes de 2002, os bolivianos ocupavam a Praça Padre Bento, no Pari, para a realização das suas festas pátrias e devocionais. Contudo, houve conflito com os moradores do bairro que fizeram um abaixo assinado, pedindo a saída dos bolivianos do local. Os moradores acusavam os imigrantes de sujar a praça e argumentavam que as festividades estavam atraindo assaltantes e traficantes de drogas. Uma faixa foi colocada na praça com o seguinte dizer: "A praça é nossa! Exigimos respeito estamos aqui há mais de cem anos". Depois de longa negociação, a prefeitura cedeu aos imigrantes um espaço no mesmo bairro, o local foi denominado Praça Kantuta. 
Apesar da descrição deste conflito, em A1 apresenta-se a ideia de que a imigração boliviana na cidade de São Paulo não se caracteriza pelo confinamento de bolivianos em guetos, estariam os brasileiros mais abertos ao diálogo com culturas que parecem estranhas e distantes: "Isto se deve ao fato de que tanto eles (bolivianos), quanto nós (brasileiros), temos em comum influências das três matrizes formadoras de nossa cultura latino americanas, a saber, a iberoamericana, a indígena e a africana" (BAENINGER, 2012, p. 32).

Gostaríamos de problematizar este primeiro trecho recortado de $A 1$, pois segundo ele, parece, pelo menos pelo viés histórico, que entre brasileiros e bolivianos predominam fatores de similaridade. Entretanto, pelo menos duas ponderações devem ser feitas.

A primeira ponderação diz respeito a esta tal "latinidade" que nos une. Se pensarmos de um ponto de vista estritamente geográfico a fim de dimensionar a relação espaço/identidade, é possível, no âmbito continental, dizer que somos todos latinos. Embora próximo geograficamente dos demais países da América do Sul, por fazer fronteira com quase todos (a única exceção é o Chile), o Brasil distancia-se pelo fator linguístico, uma vez que é o único país sul-americano lusófono.

Alcoff (2006, p. 246), em "Visibles identities", ao tratar da identidade dos latinos nos Estados Unidos, problematiza o efeito homogeinizador do emprego do termo "latino", lançando uma série de questões a respeito do que ou de quem este conceito designa:

Are Latinos a race, an ethnicity, or some combination? What does it mean to have hybridity as the foundation of an identity, as is the case for mestizos and most Latinos? The term "Latino"signifies people from an entire continent, subcontinent, and several large islands, with diverse racial, national, ethnic, religious, and linguistic aspects to their identity.

Given all this internal diversity, is "Latino" a meaningful identity at all?

As questões levantadas pela autora levam a refletir, sobretudo, na língua como fator homogeneizador da identidade. Isto porque se nos Estados Unidos os latinos são caracterizados como spanish speakers; no Brasil, por sua vez, embora sejamos latinos, não somos falantes do espanhol. Sendo assim, a herança linguística iberoamericana que recebemos nos distancia. Voltaremos à questão do idioma quando tratarmos do espaço escolar na análise de A2.

A segunda ponderação se refere à matriz indígena formadora de nossa cultura latina. Não há dúvidas de que ambos os países têm sérias pendências com a população indígena, mas na Bolívia a presença indígena é mais fortemente marcada. No Brasil, não parece próxima a eleição de um índio para presidente da República, raramente reconhecemos o indígena como constituinte de nossa identidade, a figura do índio é, muitas vezes, ligada ao primitivo. Deste modo, o fato de os bolivianos possuírem um biotipo que de maneira indiscriminada associamos à figura do índio, nos afasta.

Quanto à herança deixada pela terceira matriz, a africana, o autor se limita a dizer que existem semelhanças entre algumas danças bolivianas de origem africana como a Morenada e a Caporales e as Congadas e Maracatus brasileiros.

Feitas as ponderações, voltemos à questão do espaço. A Praça Kantuta tornou-se palco da festa de Alasitas, da região de La Paz, que acontece no dia 24 de janeiro. Anteriormente à chegada os espanhóis, a deidade chamada Ekeko ou "o deus da abundância", era representado por uma escultura nua com traços indígenas e exibia um generoso falus como símbolo da fertilidade e virilidade. Mais tarde, a Igreja Católica vestiu Ekeko com trajes que lhe deram um aspecto mais mestiço, ocultou a função simbólica fertilizadora, dando maior relevância ao poder da divindade em prover os bens materiais necessários à sobrevivência.

Atualmente, num contexto de migração Ekeko passou a ser o "patrão da fortuna", a ele são oferecidas miniaturas de carros, de casas, de malas, de passaportes, de máquinas de costura e também de 
notas (euros, reais ou dólares). Em A1 encontramos uma nota de rodapé na qual consta que certa vez, na ocasião da festa, um boliviano foi preso por portar dinheiro falso, na verdade eram as réplicas que seriam oferecidas à divindade. Embora outras festas como o carnaval, por exemplo, ainda sejam realizadas na Praça Kantuta, os bolivianos não puderam mais celebrar a Alasitas no mesmo local, pois,

[...] como a festa acontece numa data que é dia de trabalho normal para os brasileiros, a praça não pode mais ser utilizada para este fim porque impedia o trânsito de pessoas que moram nas imediações do local, bem como de alunos que estudam numa escola técnica que fica em frente a referida feira. (SILVA, 2007, p. 23).

O Memorial da América Latina é outro local que tem servido de palco às festas pátrias e devocionais bolivianas, conforme consta em A1 este espaço tem sido negociado desde 2006,

[...] quando as festas de devoção às Virgens de Copacabana e de Urkipiña deixaram de ser realizadas na Igreja de Nossa Senhora da Paz, sede da Pastoral do Imigrante. $\mathrm{O}$ ciclo de festas neste local durou precisamente onze anos e foi marcado por conflitos e negociações junto à instituição eclesial e os bolivianos (Silva, 2003). A mudança de local se deu, por um lado, em razão do aumento de participantes nas festividades, gerando conflitos com moradores do bairro onde se localiza a referida igreja e, por outro, porque os bolivianos estão mobilizados na veiculação de uma nova imagem de si mesmos, e as festas, como um fato social total, na perspectiva maussiana, passou a ser locus de uma construção identitária enquanto positividade. (SILVA, 2007, p. 24).

Em relação ao excerto acima, primeiramente, queremos chamar a atenção para o fato de que embora o autor de A1 afirme que São Paulo é uma metrópole aberta ao diálogo com culturas distintas, o conflito entre os bolivianos e os moradores dos bairros nos quais suas manifestações culturais são realizadas é uma recorrência. Em segundo lugar, cabe problematizar esta "nova imagem" que os bolivianos ${ }^{1}$ querem

1. 0 autor cita algumas associações que estariam empenhadas na construção desta "nova imagem", tais como a de residentes bolivianos, construir de si mesmos, uma vez que no próprio artigo há indícios de que alguns bolivianos demonstraram-se insatisfeitos com a espetacularização de suas festividades em nome uma nova construção identitária.

Assim, podemos dizer que em A1, devido às condições adversas enfrentadas no novo território no qual se encontram os bolivianos, as manifestações culturais ganharam um caráter nômade que pode ser tomado como indício de resistência e tentativa de manutenção de certa unidade identitária num país estrangeiro.

\section{ESPAÇO ESCOLAR: A IDENTIDADE SILENCIOSA}

A pergunta inicial presente em A2 é a seguinte: como pensar a educação de pessoas desenraizadas numa das instituições mais territorializadas do mundo? Como já dissemos anteriormente, as autoras procuram verificar se estão sendo cumpridas as condições da educação enquanto direito humano para os imigrantes bolivianos residentes na cidade de São Paulo, ou seja, se a educação é disponível, acessível, aceitável e adaptável.

Deste modo, Magalhães e Schilling (2012) escrevem a narrativa da inserção de estudantes bolivianos nas escolas de São Paulo a partir de três eixos: do ingresso na escola e a regularização dos estrangeiros no país, da relação dos estudantes bolivianos e suas famílias com a comunidade local e das expectativas dos bolivianos em relação à escola. Aqui, interessa-nos, sobretudo, os relatos que dizem respeito à interação no ambiente escolar.

O primeiro entrave ao acesso pontuado pelas autoras diz respeito aos documentos exigidos no ato de matrícula. A condição de indocumentado afasta os imigrantes da instituição escolar. A saída do país

a Gastronômica, Cultural e Folclórica Bolivianos Padre Bento e também, Conjuntos Folclóricos Bolívia/Brasil. 
de origem pode ser encarada como um ponto de virada nas narrativas de si, ou um como uma "self-generated peripeteia” (BRUNER, 2002, p. 83), mas ao chegar ao país estrangeiro esta narrativa deve ser lida pelo outro. Tanto mais escrita for esta narrativa, mais identificada como legítima ela será. Com isso queremos dizer que em nossa sociedade, as narrativas escritas têm valor infinitamente maior no sentido de que elas se constituem como documento para que se escreva a História.

Deste modo, seria possível conjugar História e narrativa na esteira do que propõe Hayden White. Para ele a narrativização dos acontecimentos é sempre uma alegoria, é a imposição de uma forma discursiva sobre os eventos. Assim, embora os artigos aqui tomados como objeto de análise explorem as narrativas orais dos bolivianos, é a escrita acadêmica que as legitima. A História apresentada como verdade é, quase sempre, escrita:

As is well-know and genrally conceded, the possibility of representing the development of certain cultures in a specifically "Historical" kind of discurse is based on the circunstance that these cultures produced, preserved, and used a certain kind of record, written records. (WHITE, 2003, p. 32).

Ultrapassada a barreira do documento para o ingresso na escola, a língua escrita passa a representar um problema de outra ordem, uma vez que as dificuldades nas atividades, envolvendo a escrita da língua portuguesa se tornam latentes. A diferença idiomática é tratada pelas autoras como um obstáculo ao acesso pleno à educação:

Outra questão foi a da relação espanhol-português. Entre as pessoas com quem conversamos nenhuma ingressou imediatamente na escola logo que chegou em São Paulo. Mesmo as que relatam uma trajetória escolar exitosa, contam que fizeram uma pausa - na maioria das vezes com duração de um ano - motivada pela insegurança com o novo idioma. A língua aparece como uma barreira inicial para todos que imigram. $\mathrm{Na}$ ausência de espaços de sociabilidade com brasileiros/as, a principal aliada para a aprendizagem do idioma, con- tam, é a televisão: "Eu parei de estudar por um ano por conta da escrita, Mas depois entrei na quinta série" [...] (E5, 17 anos). "Está tudo bem eu só tenho o problema da escritura... só esta dificuldade no português mesmo"[...] (E4, 19 anos). (MAGALHÃES; SCHILLING, 2012, p. 51).

Ao longo do texto, as autoras afirmam que o oferecimento do reforço escolar na disciplina Português seria um dos caminhos para que a escola se tornasse mais acessível e adaptável às necessidades dos estudantes bolivianos. Aliás, quando se fala em educação regular de alunos estrangeiros, as chamadas "aulas de reforço" parecem ser a primeira medida a ser pensada, em termos de "política de identidade". Entretanto, é possível questionar a validade desta medida, isto porque mesmo para alunos brasileiros pertencer às turmas de reforço os identifica como aquele que não sabe ou que sabe menos.

No caso de alunos estrangeiros há ainda outro agravante: se a intenção é que aprendam o português, isolá-los com apenas um falante nativo, o professor de português, não parece ser a melhor das estratégias de interação para que avancem no idioma. Professores de português para alunos chineses, por exemplo, se queixam de que, muitas vezes os estudantes se isolam ao falar entre si em seu próprio idioma.

Segundo relatos colhidos em A2, a insegurança no domínio da língua portuguesa, somado a uma postura mais disciplinada e uma relação de respeito e reverência à autoridade do professor faz com que a voz dos estudantes bolivianos seja pouco ouvida no ambiente escolar:

Eu sei que eles têm domínio do português, mas eles têm medo de se expor. Então eles falam muito pouco, falam muito baixo, tem uns que nem respondem a chamada. $E$ eles não perguntam. Eles não falam, então tem alunos que eu sei a voz porque eu vou lá e converso com ele, senão nunca escutaria. Você pergunta; "Você mora aqui na esquina?” ele responde: “ - Não, não sei”. Eles falam "não sei” para a maior parte das perguntas que você faz [...] Daí eu fiz alguns seminários, mas ele não participava. Ele preferia ficar com "zero" do que falar (relato da professora) (MAGALHÃES; SCHILLING, 2012, p. 53). 
Podemos notar que embora a professora afirme que os alunos dominam o português, eles preferem responder às perguntas dizendo "não sei". 0 que eles não sabem? O comportamento do aluno no seminário parece contradizer com outra característica atribuída pelos brasileiros (professores e estudantes) à identidade dos bolivianos, a disciplina para os estudos:

Os professores elogiam muito nós, bolivianos, a gente é bem educado na sala, a gente não briga com o professor, é porque a gente estuda, tiramos notas. Aí eles (os brasileiros) ouvindo isso falam "- ah, você é muito bonitinho, tem que fazer bagunça”" (relato de aluna boliviana, 17 anos) (MAGALHÃES; SCHILLING, 2012, p. 53).

Sendo assim, os estudantes têm de responder a ao menos três demandas: a de serem bons alunos num país estrangeiro, a de superarem sua introspecção e a de socializar-se com brasileiros mesmo sendo "bonitinhos". Talvez um modo de facilitar a interação fosse perguntar o que eles sabem e, a partir destes saberes, estabelecerem vínculos entre bolivianos e brasileiros, quem sabe assim se rompesse o silêncio que, aos poucos, camufla a identidade: Tem alguns que você pergunta "você é boliviano?". "Não, eu sou brasileiro meu pai que é boliviano", como se tivesse algum problema, como falavam os nordestinos antes (relato da professora 3) (MAGALHÃES; SCHILLING, 2012, p. 55).

\section{ESPAÇO LABORAL: A IDENTIDADE INCLASSIFICÁVEL}

Em A3, Cymbalista e Xavier (2007) trazem conceitos de padrões de inserção territorial definidos internacionalmente, são eles: os guetos (cuja maior referência são os existentes nos EUA, com abundante presença de negros e hispânicos, localizados nas áreas centrais das metrópoles, com grande abrangência territorial, marcados pela utilização de prédios abandonados como moradia; entre seus habitantes há uma grande margem de desempregados); as banlieues (a maior referência é a França, consiste em conjuntos habitacionais construídos pelo poder público, têm em média menos de 30 mil habitantes, situam-se nas periferias das grandes cidades e possuem grande diversidade étnica); os enclaves étnicos (concentração de grupos específicos baseadas em escolhas voluntárias por critérios de vizinhança, de manutenção da língua, da religião ou da cultura de um modo geral, costumam ser menos estigmatizados. Os autores tomam como exemplo os enclaves existentes em Toronto, Canadá), e os contingentes desalojados (agrupamento de pessoas vítimas de perseguições políticas, religiosas ou guerras civis).

A partir dessas definições os autores investigam o modo como se dá o padrão de inserção territorial dos imigrantes bolivianos na cidade de São Paulo:

Conhecer melhor o padrão de inserção territorial dessa comunidade a partir de suas próprias especificidades - e não a partir das preconcebidas categorias internacionais ou procurando em vão a repetição do padrão histórico de imigração branca e japonesa em São Paulo, que não se reproduz nos bolivianos recém-chegados - é um primeiro passo para a construção da interface adequada entre São Paulo e os bolivianos, interface ainda inexistente. (CYMBALISTA; XAVIER, 2007, p. 122).

Não fica claro ao longo do artigo o que seria "interface adequada". No entanto, os autores fazem um julgamento positivo de projetos pontuais voltados aos imigrantes bolivianos tais como a elaboração de uma cartilha (em espanhol) voltada à saúde da mulher em razão da dificuldade encontrada pela Coordenadoria de Saúde da Móoca (2003) em lidar com gestantes bolivianas que, por razões culturais, se negavam a fazer cesariana.

A narrativa prossegue a partir da análise das entrevistas concedidas por mais de 50 bolivianos. As condições de trabalho é o foco de interesse, até porque o trabalho é, na maioria das vezes, o motivo da vinda. Sendo assim, a localização das oficinas de costura surge como primeiro fator determinante na inserção territorial dos bolivianos. Cerca de $40 \%$ das oficinas localizam-se nos bairros do Brás, Bom Reti- 
ro, Belém e Barra Funda, há também aquelas que se situam na Casa Verde, Limão, Vila Maria, São Miguel Paulista e até em outros municípios como Guarulhos. Devido aos altos custos com aluguel e à fiscalização das condições de trabalho, as oficinas estão migrando para regiões mais periféricas da cidade.

As condições de trabalho nas oficinas são o segundo fator determinante na inserção territorial dos bolivianos, pois a jornada de trabalho costuma ter mais de oito horas e muitos trabalhadores moram nas oficinas ou em torno delas.

Esse enclausuramento para dentro da casa-oficina, define parte significativa da inserção desse grupo no território da cidade, e é importante para pensar a pouca visibilidade do grupo nos espaços públicos, sistemas de transporte e outros locais abertos da cidade [...]. (CYMBALISTA; XAVIER, 2007, p. 126).

Assim, os autores apontam que os momentos de socialização dos bolivianos na cidade se dão como uma forma de "privacidade coletiva”, uma vez que locais como a Praça Kantuta e a Rua Coimbra, no Brás, destinam-se a momentos pontuais nos quais os bolivianos socializam entre si.

Ao final, Cymbalista e Xavier concluem que a inserção territorial boliviana na cidade de São Paulo não se encaixa em nenhuma das categorias internacionalmente estabelecidas. Deste modo, seria necessário que estes imigrantes tivessem uma maior visibilidade na cidade, pois ainda segundo os autores, "trata-se de um grupo praticamente ausente das estatísticas públicas, politicamente pouco organizado e pouco interessado em ser estudado" (CYMBALISTA; XAVIER, 2007, p. 122).

\section{CONSIDERAÇ̃̃ES FINAIS}

Alcoff (2006) nos oferece o conceito de horizontes (oppennings) a partir dos quais são construídas verdades. Ao tomar as narrativas acadêmicas como horizontes, podemos dizer que pelo menos três verdades sobre a identidade dos bolivianos foram forjadas pelo outro acadêmico: a de que eles buscam construir uma nova imagem de si diante dos paulistanos, a de que são vítimas de um sistema educacional excludente e a de que sua socialização com não bolivianos é restrita.

Cada uma das narrativas, ao seu modo, aponta para a urgência da visibilidade, isto é, para a importância de tomar a comunidade boliviana como objeto de estudo a fim de que venha a existir uma relação mais harmoniosa entre esta e a metrópole. Contudo, tal reivindicação por visibilidade se dá numa lógica universalizante. Em A1, todos os bolivianos querem construir uma nova imagem de si; em A2 o acesso à educação já é tomado, de saída, como um direito humano universal e por fim, em A3 embora as categorias gerais de inserção territorial se demonstrem insuficientes para os bolivianos em São Paulo, a "privacidade coletiva" acaba por ser tomada como um padrão de inserção.

Todas as generalizações realizadas por cada uma das narrativas é característica intrínseca da forma que assumem, pois o método científico é em si uma perspectiva generalizante e universalista. A noção de narrativa contém uma ambiguidade do mesmo tipo que encontramos no termo história. A narrativa é a um só tempo, um modo de discurso, uma maneira de falar e um produto da adoção deste mesmo discurso. Quando este discurso é usado para representar eventos reais, o resultado é um tipo de narrativa com marcas linguísticas, gramaticais e retóricas específicas.

No caso das narrativas acadêmicas os eventos reais foram situados em diferentes espaços e com diferentes sujeitos, logo não é possível essencializar as identidades depreendidas na expressão "os bolivianos". Certamente os bolivianos que aqui vivem já não são os mesmos para os que lá ficaram. E os filhos dos 
bolivianos aqui nascidos, quão bolivianos são? “[...] eu sou brasileiro, meu pai é que é boliviano".

O espaço no qual se transita em busca de um local para manifestar suas tradições, no qual se silencia para ouvir o emaranhar de línguas (português/espanhol) que parecem tão próximas e ao mesmo tempo distantes e, enfim espaço no qual os imigrantes bolivianos se inserem, alheios às categorias preestabelecidas é já um novo constituinte de sua identidade como imigrantes em São Paulo. Este movimento identitário constante é, sem dúvida, um dos motores da dinâmica da cidade caracterizada pelo dissenso e pela pluralidade.

\section{REFERÊNCIAS}

ALCOFF, L. Visible identites: Race, gender, self. Oxford University Press, 2006

BAENINGER, Rosana (Org.). Imigração boliviana no Brasil. Campinas: Grupo de estudos de população NEPO/ Unicamp, Fapesp, Cnpq, Unfpa, 2012.
BRUNER, J. Making stories: Law, literature, life. Harvard University Press, 2002.

CYMBALISTA, Renato; XAVIER, lara Ronilk. A comunidade boliviana em São Paulo: definindo padrões de territorialidade. Cadernos Metrópole, v.17, 2007. p.119-133.

MAGALHÃES, Giovanna Modé; SCHILLING, Flávia. Imigrantes da Bolívia na escola em São Paulo: Fronteiras do direito à educação. Revista Proposições, v.23. n.1, Campinas, jan-abr. 2012. p.43-63.

MIGNOLO, W. D. Desobediência epistêmica; a opção descolonial e o significado de identidade em política. Cadernos de Letras da UFF - Dosssiê: Literatura, língua identidade, n.34, 2008. p.287-324.

SILVA, Sydney A. Bolivianos em São Paulo: dinâmica cultural e processos identitários, 2007.

WHITE, $\mathrm{H}$. The question of narrative in the Contemporary Historical Theory. London, 2003. 